clinical evidence of the key role played by sex hormones in general and the oestrogens in particular in the aetiology of postmenopausal and senile osteoporoses. The chapter dealing authoritatively with this subject is one of the more interesting sections of the book meant, no doubt, to be read by doctors of various disciplines. The book contains no less than three chapters consecrated to basic information on normal and pathological bone structures, calcium metabolism and classification of bone diseases. When discussing the diagnosis, special emphasis is laid on the evaluation of the various diagnostic methods, laboratory investigations, new radiological techniques and a glimpse is allowed into the field of the more sophisticated quantitative measurements.

Not unexpectedly, no new therapeutic discovery is reported. As mentioned already, the authors are enthusiastic about the value of oestrogens which they believe to be the proved remedy for both prevention and treatment of established osteoporosis in the postmenopausal and older women. Their discourse on the benefits, complications and contraindications of long-term oestrogen administration is based on detailed study of published work and vast personal clinical practice spanning over a period of more than twenty-five years. No one would quarrel with their criticism of doctors who still prescribe so many unproved remedies.

The section on rehabilitation and nursing outlines the general principles for the prevention and care of those afflicted with invalidism resulting from all forms of osteoporosis. Whether in the rehabilitation unit or orthopaedic ward, the multidisciplinary approach is advocated. This is to ensure a co-ordinated effort by all members of the remedial team to deal with the needs of the whole patient and his family, be they physical, psychological or social.

All in all it is a well written book, compact, up to date; once started one feels almost compelled to finish reading it in one go. The book contains nearly nine hundred references, and a useful subject index.

The reviewer's only criticisms are: (i) Laboratory data are not given in SI units; (ii) there are too few illustrations; (iii) the quality of some of the $X$-ray reproductions is disappointing.

This book is highly recommended to general physicians and orthopaedic surgeons and, particularly, geriatricians, physical medicine specialists and rehabilitation therapists.

\section{Epidemiology for Clinicians}

By C. J. Roberts. Pp. 198, soft cover. Tunbridge Wells: Pitman Medical, 1977. £3.50.

It is good to see this sign of resistance to the threatened takeover of epidemiology by community medicine specialists. Epidemiology is also an integral part of mainstream clinical medicine, being essential to the study of natural history, prognosis and aetiology, which in turn are necessary to rational clinical decisions.

The book is written by a professional epidemiologist with a wide experience of working with clinicians. His aim is to help doctors and students to see how epidemiological information can help them in their care of patients. The first section, based mainly on a series of examples, sets out to show the relation of epidemiology to diagnosis, prognosis, and the evaluation of treatment, prevention and screening. The second section outlines, again with examples, a few of the subject's basic methods. Unfortunately some techniques of particular clinical interest (for instance, case/control and natural history studies) get no mention. Finally, no fewer than seven appendices add some disconnected afterthoughts.

The style is clear and readable, albeit marred by misprints. The examples are often excellent, and they make the book well worth studying. However, the theoretical and methodological framework is too superficial for the book to serve either as a reference work for doctors or as a textbook fcr students.

\section{Remembering Henry}

Edited by Stephen Lock and Heather Windle. Pp. 166, soft cover, illustrated. London: British Medical Association, 1977. £3.00.

In this book over thirty contributors-neurologists, physicians, administrators lay and medical, musicians, nurses, secretaries and former university students reminisce about a man who in the words of Lord Cohen was an institution and a legend in his own lifetime. All who knew him will find it difficult to put down this book - those of us who saw him only infrequently and then briefly, will be left to ponder on what it was which made this man, who was not always right in what he said and who sometimes changed his mind without acknowledgment, so great, which he undoubtedly was. The book also contains three of Miller's more general lectures on accident neurosis, medical education and psychiatry. The BMA is to be congratulated for sponsoring this book, any profits from which will be donated to the Henry Miller Memorial Fund.

\section{Textbook of Surgery}

(4th edition)

Edited by D. A. Macfarlane and L. P. Thomas. Pp. 787, soft cover, illustrated. Edinburgh, London, New York: Churchill Livingstone, 1977. $£ 8.50$.

The fourth edition of this deservedly popular undergraduate surgical textbook appears in the now familiar economy soft cover, with the advantage of helping to fight inflation. The secret of its success has been a clearly written text supplemented by a very large number of excellent, simple and often ingenious diagrams. Considerable revisions have taken place in this new edition, especially in the endocrine and orthopaedic sections, the chapter on injury and repair, the section on Hodgkin's disease, Crohn's disease and renal transplantation. Recent advances in the use of fibre-optic instruments in endoscopy and cryosurgery have been incorporated. Two new authors join the team of contributors, which now numbers ten. This textbook can continue to be recommended to clinical students as a useful, concise and sound basis for surgical practice. 